\title{
Expression analysis of VEGF-A and VEGF-B: Relationship with clinicopathological parameters in bladder cancer
}

\author{
SYLVIE FAUCONNET ${ }^{1,2 *}$, STEPHANE BERNARDINI ${ }^{2 *}$, ISABELLE LASCOMBE ${ }^{1}$, GUILLAUME BOITEUX ${ }^{1}$, \\ ANNE CLAIROTTE $^{3}$, FRANCK MONNIEN ${ }^{3}$, ERIC CHABANNES ${ }^{2}$ and HUGUES BITTARD ${ }^{2}$ \\ ${ }^{1}$ Laboratoire de Biologie Cellulaire et Moléculaire, EA 3181, IBCT, IFR 133, Université de Franche-Comté, \\ UFR des Sciences Médicales et Pharmaceutiques, 19 rue Ambroise Paré, 25041 Besançon Cedex 3; \\ ${ }^{2}$ Service d'Urologie et d'Andrologie, CHU de Besançon, Hôpital St Jacques, 2 place St Jacques, \\ 25000 Besançon; ${ }^{3}$ Service d'Anatomie et Cytologie Pathologiques, CHU de Besançon, \\ Hôpital Jean Minjoz, 3 boulevard Fleming, F-25000 Besançon, France
}

Received October 20, 2008; Accepted December 4, 2008

DOI: 10.3892/or_00000380

\begin{abstract}
The present investigation was conducted first to determine whether correlation exists between VEGF-A and -B mRNA levels and clinicopathological parameters and to assess their prognostic value in bladder cancer, then to clarify the expression level and biological significance of VEGF-A isoforms. Total RNA was isolated from 37 specimens of bladder cancer. Northern blot analysis revealed that VEGF-B mRNA was not expressed either in normal urothelium or in bladder cancer and detected three VEGF-A transcripts of $5.2,4.5$ and $1.7 \mathrm{~kb}$ in length, respectively. The VEGF-A transcript levels were greater in cancer tissues than in normal urothelium. They were significantly higher in pT2-T4 than in pTa and pT1 urothelial tumors and thus, were correlated to the pathologic stage. Contrary to the $4.5 \mathrm{~kb}$ transcript, elevated expression of the 5.2 and $1.7 \mathrm{~kb}$ transcripts was correlated with the histologic grade and the presence of carcinoma in situ. Patients with higher VEGF-A mRNA levels had a significantly shorter survival without progression compared to those with lower levels. Three VEGF-A splice variants were detected by Southern blotting namely, VEGF121, 165 and 189. The expression intensity of each isoform was evaluated by quantitative real-time RT-PCR in 20 new fresh frozen recent tumors. VEGF121 and VEGF165 were expressed at the similar level. On the contrary, they were significantly more expressed than VEGF189 $(\mathrm{p}<0.05)$. The three isoforms were higher expressed in pT2 bladder cancers than in pTa
\end{abstract}

Correspondence to: Dr Sylvie Fauconnet, EA 3181, IBCT, IFR 133, Université de Franche-Comté, UFR des Sciences Médicales et Pharmaceutiques, 19 rue Ambroise Paré, F-25041 Besançon Cedex 3, France

E-mail: sylvie.fauconnet@univ-fcomte.fr

*Contributed equally

Key words: bladder cancer, prognostic marker, VEGF-A, VEGF-B, isoform, mRNA tumors $(\mathrm{p}<0.05)$. There was only a significant correlation between the increased expression level of VEGF121 and 165 and the histological grade of the lesion $(p<0.05)$. To conclude, VEGF-A mRNA level is a potential prognostic indicator of progression in bladder cancer as well as the expression level of the different VEGF-A splice variants.

\section{Introduction}

Urothelial carcinoma is the most common solid malignancy of the bladder. Eighty percent of all newly diagnosed cases are non-invasive and stroma-invasive tumors confined to the urothelium ( $\mathrm{pTa}$ ) or the lamina propria (pT1) respectively and the other $20 \%$ are muscle-invasive carcinomas $(\geq \mathrm{pT} 2)$. More than $60 \%$ of pTa tumors will recur at least once and progress to infiltrating or less differentiated neoplasms in $5-10 \%$ of cases (1). The recurrence rate of pT1 bladder tumors is high (80\%) after transurethral resection (TUR) (2) and $40 \%$ of them will progress to muscle-invasive disease with a poorer prognosis and are therefore potentially lethal (3). Muscle invasive tumors have a poorer prognosis (4) since $50 \%$ of these patients will relapse with metastatic disease within 2 years of treatment (5). Since the clinical outcome of stroma-invasive (pT1) bladder tumors is relatively unpredictable, search for novel prognostic factors that could give information independent of classical predictors to improve the biological assessment of the pT1 tumors could be of great clinical value for taking charge of the patients.

Tumor vascularization plays a fundamental role in neoplastic processes and is essential for tumor progression and metastatic spread of solid tumors. Vascular Endothelial Growth Factor (VEGF or VEGF-A) is considered to be one of the most important angiogenic regulators in tumor angiogenesis (6). To date, several different isoforms have been isolated resulting from an alternative splicing of VEGF-A mRNA between exons 5 and 8 (7), namely two larger variants, VEGF189 and VEGF206 and smaller forms, VEGF121, VEGF145 and VEGF165.

The isoform 145 of VEGF-A is observed preferentially in carcinomas of the female reproductive system (8). Each 
isoform is predicted to have a characteristic extracellular localization based on biochemical differences. The larger isoforms bind neuropilin, matrix, and cell surface heparin proteoglycans, and are thought to act locally. The smaller isoforms do not display the heparin proteoglycan binding region and may diffuse to sites distant from the site of synthesis (9). The most frequent isoform is VEGF165 which is expressed in most tissues (10) and although it is a diffusible protein, a significant fraction remains cell and extracellular-matrix associated (11). There are data in the literature concerning the detection of a less frequent spliced form VEGF183 (12).

Several VEGF-related genes, including VEGF-B (13) have also been isolated. VEGF-B is expressed as two isoforms produced by alternative splicing both of which are very similar to VEGF165 $(13,14)$. VEGF binds to high affinity tyrosine kinase receptors, VEGFR-1/Flt1 and VEGFR-2/KDR (12) whereas VEGF-B can compete with VEGF-A only for binding to VEGFR-1 (15). At present the role of VEGF-B has not been completely clarified. VEGF-B is a weak mitogen for endothelial cells (13). Most importantly, nothing is known about its expression in bladder cancer.

On the contrary, several reports described increased expression of VEGF-A in bladder cancer tissue, compared with normal urothelium $(16,17)$, as well as in biological fluids (serum and urine) of patients with bladder cancer. Nevertheless, conflicting studies have questioned the prognostic value of VEGF-A within the tumor. O'Brien et al (17) reported that an average expression level of the vegf-A gene in non-invasive (pTa and pT1) tumors was higher than in invasive tumors and in normal tissue while Sato et al (18) demonstrated that invasive TCC expressed more vegf-A gene than non-invasive TCC.

The aim of the present investigation was: i) to examine the expression of VEGF-A and VEGF-B mRNA in bladder cancer by Northern blotting and to analyse the correlation between both VEGF subtypes expression pattern and the clinicopathologic criteria of the disease; ii) to quantify by real-time RT-PCR the expression of VEGF-A isoforms in bladder tumors, and to study their relative expression and their relationship with pathologic stage and histologic grade.

\section{Materials and methods}

Patients and sample collection. Bladder tumor samples from transurethral resection (TUR) or cystectomy specimens were obtained from two cohorts of patients. Thus, VEGF-A and -B expression was evaluated by Northern blotting in 37 cases with TCC of the bladder who underwent TUR of a primary bladder tumor between December 1996 and December 1999. VEGF-A isoform transcript levels were determined by realtime RT-PCR analysis in an independent tumor set of 20 new fresh frozen specimens. Informed consent was obtained from all patients. Total resected tissue specimens were supplied by the Department of Urology (University Hospital, Besançon, France). A part was collected for histopathologic evaluation and the remainder was immediately frozen in liquid nitrogen for total RNA extraction. The rapid freezing of bladder tumor samples immediately after TUR in liquid nitrogen is a favourable process to abolish hypoxia, which is known to increase VEGF-A expression. This avoids overestimation of the expression of this growth factor. Specimens of 5 normal bladder mucosa were obtained from bladder biopsies taken from benign prostatic hyperplasia patients who underwent transurethral surgeries. Histology features, grade, stage and presence of carcinoma in situ (CIS) were determined by pathologic examination of the TUR specimens. We assigned the bladder tumors a grade according to the WHO classification. The depth of invasion was recorded according to the 1997 tumor-node-metastasis (TNM) staging system guidelines. In all cases, muscularis propria was available for evaluation. Of the 37 patients for the Northern blot analysis, 22 had non-invasive and stroma-invasive urothelial tumors (15 pTa, 7 pT1) and 15 had muscleinvasive carcinomas (pT2-T4). Nine patients had grade 1 tumor (7 pTa, 1 pT1, 1 pT2-T4), 13 grade 2 tumor (7 pTa, 3 pT1, 3 pT2-T4) and 15 grade 3 tumor (1 pTa, 3 pT1, 11 pT2-T4). Ten patients presented also a carcinoma in situ. The median patient follow-up was 20 months (range, 6-60 months). Within the cohort of 20 patients studied in the realtime RTqPCR analysis, 15 had non-invasive and stromainvasive urothelial tumors ( 8 pTa, 7 pT1) and 5 had muscleinvasive carcinomas (pT2). Seven patients had grade 1 tumor (pTa), 4 grade 2 tumor ( 1 pTa, 3 pT1) and 9 grade 3 tumor (4 pT1, 5 pT2).

Cell line and culture conditions. RT4 and T24 bladder cancer cell lines were obtained from the American Type Culture Collection (ATCC, Biovalley, Conches, France). RT4 and $\mathrm{T} 24$ cells were maintained at $37^{\circ} \mathrm{C}$ in a $5 \% \mathrm{CO}_{2}$ atmosphere in phenol red-free $\mathrm{McCOY}^{\prime} \mathrm{s} 5 \mathrm{a}$ medium. Media were supplemented with $10 \%$ heat-inactivated fetal calf serum (FCS) (Invitrogen, Cergy Pontoise, France), 1\% antibiotic antimycotic mixture $(10 \mathrm{mg} / \mathrm{ml}$ streptomycin, 10,000 U/ml penicillin, $25 \mu \mathrm{g} / \mathrm{ml}$ amphotericin B) (Sigma, St. Quentin Fallavier, France), $2 \mathrm{mM}$ glutamine and $15 \mathrm{mM}$ Hepes (Invitrogen). Cell lines were tested for the absence of mycoplasma before RNA extraction.

Northern blotting. The commercially available kit RNeasy (Qiagen, Courtaboeuf, France) was used according to the manufacturer's guidelines for RNA isolation from bladder tumor specimens and from normal bladder mucosa. Total RNA $(30 \mu \mathrm{g})$ was size-fractionated by electrophoresis on a $1.2 \%$ agarose gel and transferred to a nylon membrane (ZetaProbe GT Genomic, BioRad, Marnes-la-Coquette, France) using vacuum blotting system. The filters were prehybridized for $5 \mathrm{~min}$ at $42^{\circ} \mathrm{C}$ in a solution containing $50 \%$ formamide, $0.25 \mathrm{M} \mathrm{NaCl}, 7 \%$ SDS, $0.12 \mathrm{M} \mathrm{Na}_{2} \mathrm{HPO}_{4}$ (pH 7.2). The hybridizations were performed for $48 \mathrm{~h}$ in the same solution at $42^{\circ} \mathrm{C}$ with the VEGF-A (19) or VEGF-B (20) cDNA probe labelled with $\left[\alpha-{ }^{32} \mathrm{P}\right]-\mathrm{dCTP}$ (NEN Life Science, Paris, France) using the random hexamer labelling method (Primea-gene Labelling System, Promega). After a rapid wash in $2 \mathrm{X}$ SSC solution at room temperature, two washes were performed for $15 \mathrm{~min}$ at room temperature in $2 \mathrm{X} \mathrm{SSC}, 0.1 \%$ SDS and $0.5 \mathrm{XSC}, 0.1 \% \mathrm{SDS}$, respectively. The final wash was performed for $15 \mathrm{~min}$ at $55^{\circ} \mathrm{C}$ in $0.1 \mathrm{X} \mathrm{SSC}, 0.1 \% \mathrm{SDS}$. Blots were stripped $(0.1 \% \mathrm{SSC} ; 0.5 \% \mathrm{SDS})$ between each hybridization. Total RNA samples on each blot were adjusted to obtain a consistent signal for a housekeeping gene across 
all lanes. Equal loading of total RNA on the blots was checked by probing with the respective mouse $\beta$-actin probe (1200 bp) labelled with $\left[\alpha_{-}{ }^{32} \mathrm{P}\right]-\mathrm{dCTP}$ to normalize the experiments. The same blot was hybridized with VEGF-A or VEGF-B or mouse $B$-actin probes. For each probe, blots were exposed at the same time and thus could be compared among themselves. The VEGF-A, VEGF-B, and $B$-actin mRNA were quantified using PhosphoImager analysis (Molecular ImagerR System, GS-505, Biorad).

Reverse transcription-polymerase chain reaction ( $R T-P C R)$ and Southern blotting for VEGF-A isoform detection. RT4 and T24 cells were seeded in 12 or 6-well plates at a concentration of $8 \times 10^{5}$ or $4 \times 10^{5}$ cells per well respectively in McCOY's 5a medium supplemented with 5\% FCS. Confluent cells were incubated in serum-free McCOY's 5a medium for $24 \mathrm{~h}$. After this period, total RNA was isolated using the commercially available kit TRI Reagent (Molecular Research Center, Euromedex, Souffelwyersheim, France) according to the manufacturer's recommendations. The commercially available kit RNeasy (Qiagen) was used according to the manufacturer's guidelines for RNA isolation from bladder tumor specimens and from normal bladder mucosa. Contaminating genomic DNA was removed with a RNase-free DNase I treatment (Invitrogen) according to the manufacturer's instructions. Total RNA (5 $\mu \mathrm{g})$ was then reverse-transcribed with a random hexamer as a primer and $50 \mathrm{U}$ of MMLV RT (Promega, Lyon, France) for $1 \mathrm{~h}$ at $37^{\circ} \mathrm{C}$ and amplified by PCR with VEGF-A-specific primers, upstream (5'-CACAT AGGAGAGATGAGCTTC-3') and downstream (5'-CACC GCCTCGGCTTGTCACAT-3') localized on exons 4 and 8 , respectively. After 30 cycles $\left(1 \mathrm{~min}\right.$ at $95^{\circ} \mathrm{C}, 1 \mathrm{~min}$ at $62^{\circ} \mathrm{C}$, and $2 \mathrm{~min}$ at $72^{\circ} \mathrm{C}$ ), $6 \mu 1$ of the PCR products were electrophoresed through a 2\% agarose gel (MetaPhor, Tebu, Le Perray en Yvelines, France) for $5 \mathrm{~h}$ at $100 \mathrm{~V}$ and transferred to a nylon membrane (Zeta-Probe GT Genomic, BioRad) which was subsequently hybridized with a $\left[\alpha^{-32} \mathrm{P}\right]-\mathrm{dCTP}$ (NEN Life Science)-labelled cDNA VEGF-A probe (19). Probes were prepared by the random-hexamer labelling method (Prime-a-gene Labelling System, Promega) according to the manufacturer's protocol. Filters were analysed using a PhosphoImager (Molecular Imager System).

TaqMan RT-PCR assay. The real-time PCR assays were carried using a LightCycler 1.0 (Roche Diagnostics, Basel, Switzerland) with Taqman technology in $20 \mu 1$ of a reaction mixture containing 1X LightCycler Fast Start DNA Master HybProbe (Roche diagnostics) and $5 \mu 1$ of cDNA diluted 1:20. ATP5 $\beta$ (ATP synthase $\beta$ polypeptide) RTqPCR was carried out with $4 \mathrm{mM} \mathrm{MgCl} 2,500 \mathrm{nM}$ of each primer and $300 \mathrm{nM}$ of probe. The following oligonucleotide primers and probe were used for PCR amplification of $A T P 5 \beta: A T P 5 \beta$ forward: 5'-TACTGTCGCGTGCCATTGCT-3', ATP5 $\beta$ reverse: 5'-CACGGGCAACATCGTAATGC-3', ATP5 $\beta$ probe (5'Fam, 3'BHQ1) 5'-ATCCCAACATTGTTGGCA GT-3'. Samples were heated for $10 \mathrm{~min}$ at $95^{\circ} \mathrm{C}$ and subjected to 40 cycles of amplification (denaturation at $95^{\circ} \mathrm{C}$ for $10 \mathrm{sec}$, annealing and elongation at $60^{\circ} \mathrm{C}$ for $20 \mathrm{sec}$ ). Amplifications of cDNA encoding vegf-A transcripts were performed using $2 \mu 1$ of reverse-transcribed mixture. To reach high conformity of the PCR kinetics for the VEGF-A splice variants, a common forward primer ex3fo (5'-CCCTGATGAGATC GAGTACATCTT-3') located in exon 3 was designed. Amplification of each splice variant was performed exclusively with specific reverse primers spanning the variant exon boundaries: ex5/8re: 5'-ACCGCCTCGGCTTGTCAC-3' for VEGF121, spanning the boundaries of exons 5 and 8; ex5/7re: 5'-AACGCTCCAGGACTTATACCG-3' for VEGF165, spanning the boundaries of exons 5 and 7 ; ex/6re: $5^{\prime}-\mathrm{AG}$ CAAGGCCCACAGGGATTT-3' for VEGF189, located in exon 6. Quantification of the mRNA encoding for different VEGF-A isoforms was performed using the specific fluorescent hydrolyzation probe (5'-ATCCTGTGTGCCCCTG ATGCGATGCGGT-3'). Quantitative PCR was performed in a total volume of $20 \mu \mathrm{l}$ containing $0.25 \mu \mathrm{M}$ of each oligonucleotide primer, $0.1 \mu \mathrm{M}$ of specific probe and $2 \mu \mathrm{l}$ of cDNA according to the QuantiTect ${ }^{\circledR}$ probe PCR kit procedure (Qiagen). The cycling parameters were $95^{\circ} \mathrm{C}$ for $15 \mathrm{~min}$ and then 60 cycles of denaturation at $95^{\circ} \mathrm{C}$ for $8 \mathrm{sec}$, annealing at $68^{\circ} \mathrm{C}$ for $12 \mathrm{sec}$ and extension at $72^{\circ} \mathrm{C}$ for $20 \mathrm{sec}$. A sequence detection program calculated a threshold cycle number (CT) at which the probe cleavage-generated fluorescence exceeded the background signal (21).

Measurement of relative RNA expression level. We calculated the relative RNA expression level using a comparative CT method (21). Identified as the best normalization gene in human bladder cancer (22), ATP5ß was used for the reference gene. The normalized relative expression level of a target gene in an individual sample was calculated using the following formula:

$$
\frac{\left(\mathrm{E}_{\text {target }}\right)^{\Delta \mathrm{CT} \text { target (calibrator-sample) }}}{\left(\mathrm{E}_{\text {reference }}\right)^{\Delta \mathrm{CT} \text { reference (calibrator-sample) }}}
$$

in which the real-time PCR efficiency of the target gene transcript is donated by $\mathrm{E}_{\text {target }}$ and that of the reference gene transcript, by $\mathrm{E}_{\text {reference }}(21)$. Thus, the relative RNA expression level of a gene is a unitless number relative to that of the calibrator sample.

Statistical analysis. Data are presented as mean \pm SEM. Differences in total VEGF-A mRNA and VEGF-A isoform transcript expression levels according to the patient and cancer characteristics were assessed by the non parametric MannWhitney U and Kruskal-Wallis tests. Survival without progression was studied on the entire group of cases (pTa, pT1, pT2-T4 tumors). According to patient and cancer characteristics, curves were built and compared using the KaplanMeier procedure and the log-rank test. To determine the major isoform expressed in bladder tumors, comparison of means on three repeated values from 20 patients were assessed by the non-parametric Friedmann and Wilcoxon tests for paired series. A p-value of $<0.05$ was considered statistically significant.

\section{Results}

$V E G F-A$ and VEGF-B mRNA expression in TCC of the bladder and correlation with the pathologic stage. Northern 
VEGF-A

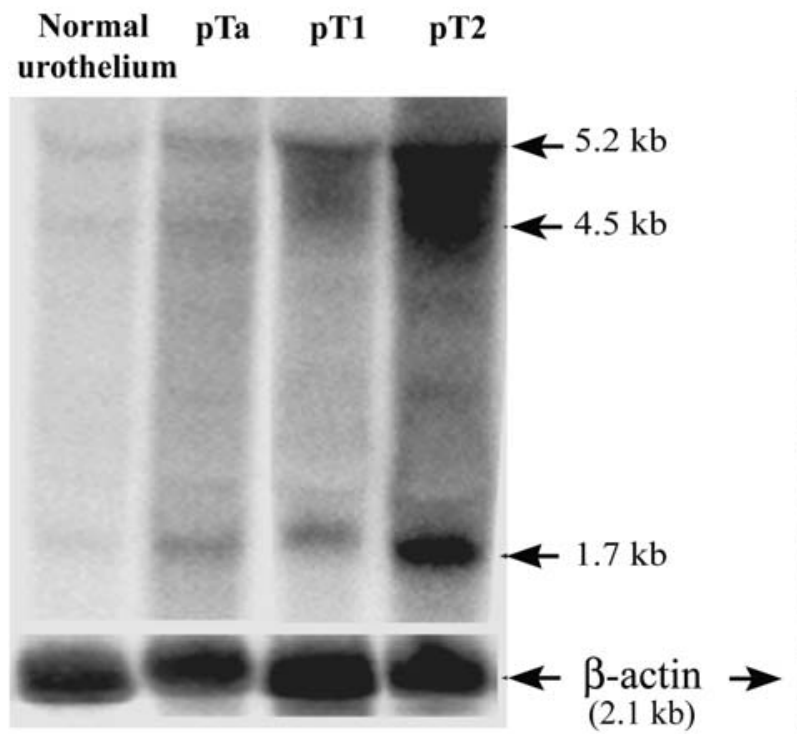

\section{VEGF-B}

Figure 1. Expression of VEGF-A and VEGF-B mRNA in normal urothelium and bladder cancer tissues. Total RNA was isolated from normal urothelium and from one specimen of pTa, pT1 or pT2 bladder tumor. RNA $(30 \mu \mathrm{g})$ was subjected to Northern blot analysis performed with [ $\left.\alpha-{ }^{32} \mathrm{P}\right]-\mathrm{dCTP}-1 \mathrm{abelled}$ probes for VEGF-A, VEGF-B, and B-actin as described in detail in Materials and methods. The probe control corresponds to the migration of the non-labelled VEGF-B cDNA probe.

Table I. Association of VEGF-A transcript levels with pathologic stage, histologic grade and presence of carcinoma in situ.

\begin{tabular}{|c|c|c|c|}
\hline & \multicolumn{3}{|c|}{ VEGF-A mRNA level } \\
\hline & $5.2 \mathrm{~kb}$ transcript & $4.5 \mathrm{~kb}$ transcript & $1.7 \mathrm{~kb}$ transcript \\
\hline \multicolumn{4}{|c|}{ Pathologic stage } \\
\hline $\mathrm{pTa}$ & $0.0180 \pm 0.008$ & $0.0235 \pm 0.010$ & $0.0226 \pm 0.010$ \\
\hline pT1 & $0.0157 \pm 0.014^{\mathrm{b}}$ & $0.0245 \pm 0.014^{\mathrm{b}}$ & $0.0204 \pm 0.009^{b}$ \\
\hline pT2-T4 & $0.0622 \pm 0.017^{\mathrm{a}}$ & $0.0684 \pm 0.014^{\mathrm{a}}$ & $0.0668 \pm 0.012^{\mathrm{a}}$ \\
\hline \multicolumn{4}{|c|}{ Histologic grade } \\
\hline G1 & $0.0130 \pm 0.006$ & $0.0236 \pm 0.0093$ & $0.0183 \pm 0.005$ \\
\hline $\mathrm{G} 2$ & $0.0243 \pm 0.0013^{\mathrm{a}}$ & $0.0373 \pm 0.015$ & $0.0280 \pm 0.011$ \\
\hline G3 & $0.0486 \pm 0.0023^{\mathrm{a}, \mathrm{c}}$ & $0.0494 \pm 0.005$ & $0.0555 \pm 0.027^{\mathrm{a}}$ \\
\hline \multicolumn{4}{|l|}{ CIS } \\
\hline No & $0.0202 \pm 0.011$ & $0.0322 \pm 0.014$ & $0.0263 \pm 0.010$ \\
\hline Yes & $0.0579 \pm 0.017^{\mathrm{d}}$ & $0.0547 \pm 0.015$ & $0.0614 \pm 0.012^{\mathrm{d}}$ \\
\hline
\end{tabular}

CIS, carcinoma in situ. Compared with pTa tumors or G1 tumors, ${ }^{a} \mathrm{p}<0.05$; ${ }^{\mathrm{p}} \mathrm{p}>0.05$. Compared with G2 tumors, ${ }^{\mathrm{c}} \mathrm{p}<0.05$. Compared with the presence of CIS, ${ }^{\mathrm{d}} \mathrm{p}<0.05$.

blot analysis revealed three VEGF-A transcripts of 5.2, 4.5 and $1.7 \mathrm{~kb}$ respectively in all samples studied. Fig. 1 is representative of the results obtained with the normal urothelium and with one specimen of each TNM stage. Table I summarizes the results of VEGF-A transcripts expression in pTa, pT1 and pT2-T4 bladder lesions. The level of VEGF-A mRNA expression was higher in bladder tumors compared with the normal urothelium. The 5.2, 4.5 and $1.7 \mathrm{~kb}$ VEGF-A transcripts levels were compared according to the TNM stage. The statistical analysis revealed that no significant difference was observed between pTa and pT1 tumors for the three transcripts $(\mathrm{p}=0.38$ for $5.2 \mathrm{~kb}$ transcript; $\mathrm{p}=0.94$ for $4.5 \mathrm{~kb}$ transcript; $\mathrm{p}=0.12$ for $1.7 \mathrm{~kb}$ transcript). On the other hand, the difference was statistically significant between pTa and pT2-T4 tumors ( $\mathrm{p}=0.0006$ for the $5.2 \mathrm{~kb}$ transcript, $\mathrm{p}=0.007$ for the $4.5 \mathrm{~kb}$ transcript, and $\mathrm{p}=0.002$ for the $1.7 \mathrm{~kb}$ 
A

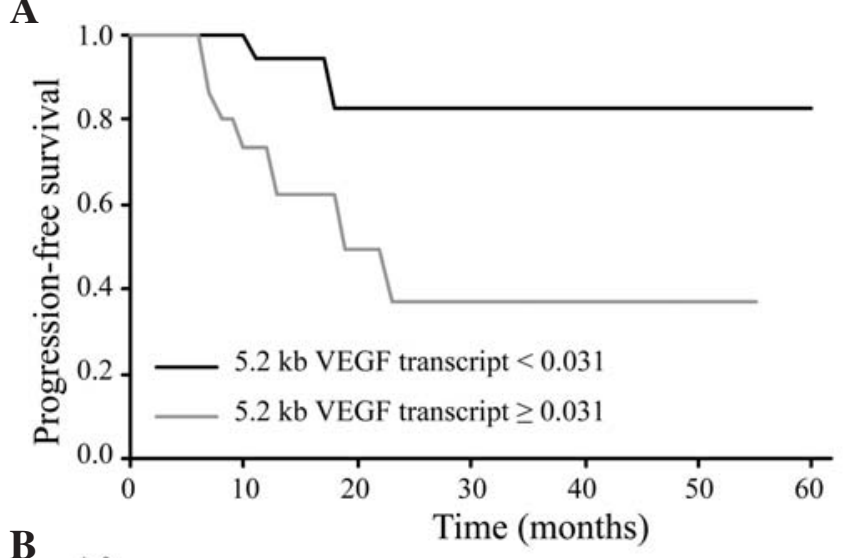

B

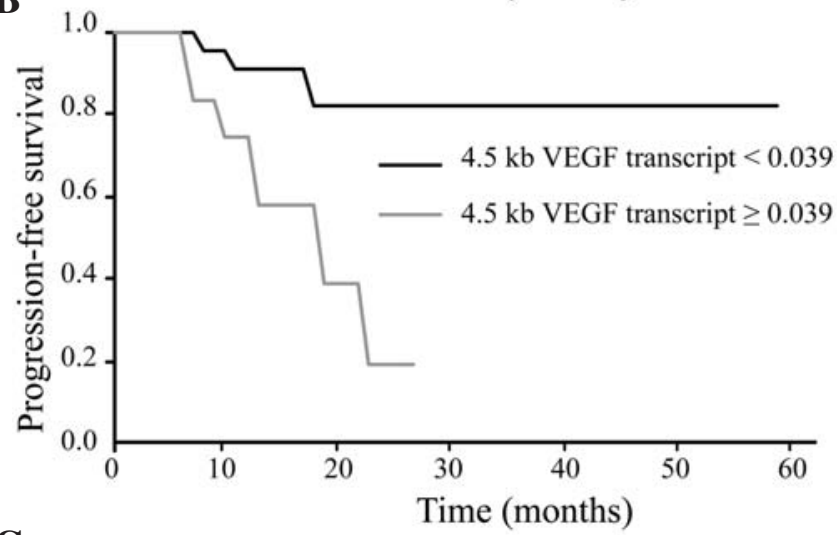

C

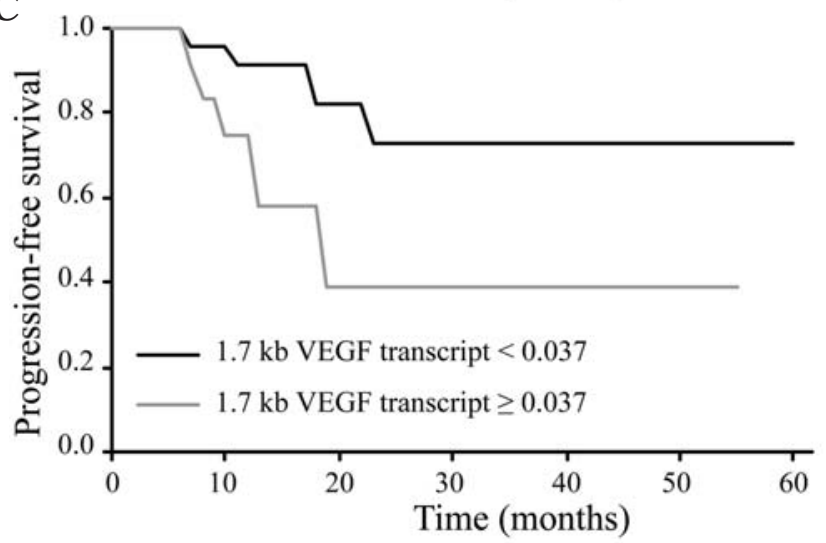

Figure 2. Kaplan-Meier progression-free survival curves in patients with TCC of different pathologic stage. (A) Relationship between progressionfree patient survival and 5.2 kb VEGF-A mRNA levels above and below the cut-off value of 0.031 ; (B) Relationship between progression-free patient survival and $4.5 \mathrm{~kb}$ VEGF-A mRNA levels above and below the cut-off value of 0.039 ; (C) Relationship between progression-free patient survival and $1.7 \mathrm{~kb}$ VEGF-A mRNA levels above and below the cut-off value of 0.037 .

transcript). In the same way, the difference was statistically significant between pT1 and pT2-T4 tumors for the three transcripts $(\mathrm{p}=0.015$ for the $5.2 \mathrm{~kb}$ transcript; $\mathrm{p}<0.05$ for the $4.5 \mathrm{~kb}$ transcript; $\mathrm{p}=0.004$ for the $1.7 \mathrm{~kb}$ transcript).

The expression pattern of VEGF-B was completely different. Indeed, VEGF-B mRNA was not expressed. It was not detected either in normal urothelium or in bladder cancer tissue. Overall, our results indicate that the expression level of VEGF-A mRNA is higher in invasive bladder carcinomas. On the contrary, within superficial tumors, VEGF-A mRNA level did not discriminate tumors invading the lamina propria.
Correlation between the expression of the VEGF-A transcripts and the histologic grade of the TCC of the bladder. The comparison of the VEGF-A transcripts expression according to the grade (Table I) revealed that for the $5.2 \mathrm{~kb}$ transcript, the difference was statistically significant between grade 1 and grade $2(\mathrm{p}=0.04)$, between grade 1 and grade $3(\mathrm{p}=0.01)$, and between grade 2 and grade $3(\mathrm{p}<0.05)$. For the $1.7 \mathrm{~kb}$ transcript, the difference was only statistically significant between grade 1 and grade $3(p=0.02)$. No significant difference was observed between grade 1 and grade 2 $(\mathrm{p}=0.28)$ and between grade 2 and grade $3(\mathrm{p}=0.13)$ for this transcript. For the $4.5 \mathrm{~kb}$ transcript, the expression level was not associated to tumor grade $(\mathrm{p}=0.29)$.

Correlation between the expression of the VEGF-A transcripts and the presence of carcinoma in situ. Unlike the $4.5 \mathrm{~kb}$ transcript, the 5.2 and $1.7 \mathrm{~kb}$ transcripts were correlated with associated carcinoma in situ $(\mathrm{p}=0.14, \mathrm{p}=0.002$ and $\mathrm{p}=0.007$, respectively) (Table I).

Relationship between VEGF-A mRNA level and progressionfree survival. The progression-free survival analysis has been performed on the entire group of 37 patients without distinguishing non-invasive and stroma-invasive urothelial tumors and muscle-invasive carcinomas. The purpose was to determine whether the evaluation of VEGF-A mRNA expression in the tumor could predict the tumor progression and the patient outcome. Thus, within the entire group of cases, the mean value of VEGF-A was 0.031 for the $5.2 \mathrm{~kb}$ transcript, 0.039 for the $4.5 \mathrm{~kb}$ transcript and 0.037 for the $1.7 \mathrm{~kb}$ transcript. Patients were therefore classified into two groups (high VEGF-A expression group and low VEGF-A expression group) based on a cut-off value corresponding to the mean value of VEGF-A calculated for each transcript. The progression-free survival curves for patients with high or low VEGF-A transcripts levels are shown in Fig. 2. There was evidence that survival without progression was shortened in patients with a VEGF-A mRNA level higher than the cut-off value previously defined $(0.031$ for the $5.2 \mathrm{~kb}$ transcript, 0.039 for the $4.5 \mathrm{~kb}$ transcript, and 0.037 for the $1.7 \mathrm{~kb}$ transcript $)(\mathrm{p}=0.03, \mathrm{p}=0.006$ and $\mathrm{p}=0.04$, respectively) compared with patients expressing lower VEGF-A mRNA levels than this cut-off value. The progression-free survival analysis revealed that after a follow-up of 25 months, the overexpression of the 5.2 and $1.7 \mathrm{~kb}$ transcripts led to the progression of the disease in $62 \%$ and $60 \%$ of cases, respectively. In return, the overexpression of the $4.5 \mathrm{~kb}$ transcript led to the progression of the disease in $80 \%$ of cases.

VEGF-A isoforms expression in urothelial tumors and bladder cancer cell lines. As demonstrated above, the different VEGF-A transcripts have a prognostic value. Thus, we analysed the VEGF-A isoform expression pattern. As shown in Fig. 3, RT-PCR assay followed by a Southern blot analysis revealed three bands with 303, 234 and 99 bp in size corresponding respectively to VEGF189, VEGF165 and VEGF121 in pT1 and pT2 bladder tumors and in RT4 and T24 bladder cancer cell lines. RT4 cells are derived from a well differentiated grade 1 papillary tumor and T24 cells are derived from an undifferentiated grade 3 carcinoma. These 


\section{pT1 pT2 RT4 T24}

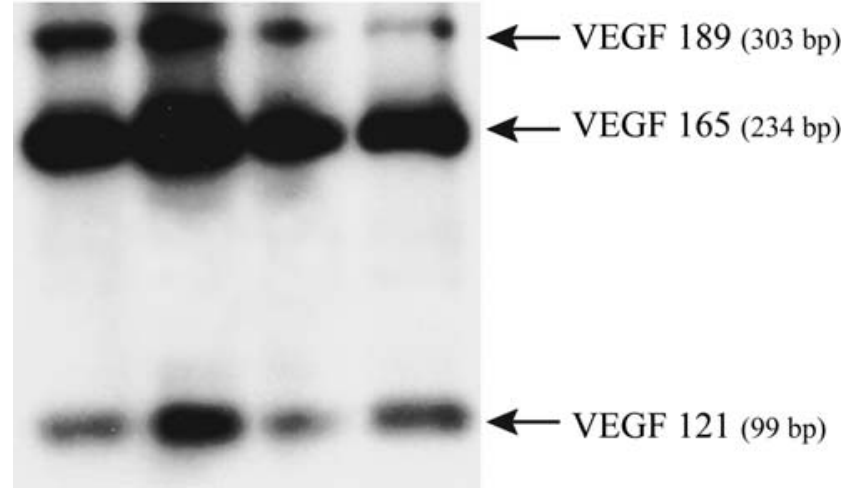

Figure 3. Expression of different VEGF-A isoforms by Southern blot analysis Total RNA was isolated from one specimen of pT1 or pT2 bladder tumor, and from RT4 and T24 cells. RT-PCR assay using specific primers for VEGF-A was performed as described in Materials and methods. The PCR products were electrophoresed on a $2 \%$ agarose gel and transferred onto a nylon membrane which was subsequently hybridized with a $\left[\alpha-{ }^{32} \mathrm{P}\right]-\mathrm{dCTP}-$ labelled cDNA VEGF-A probe. Filters were analysed using a PhosphoImager (Molecular ImagerRSystem, GS-505, Biorad).

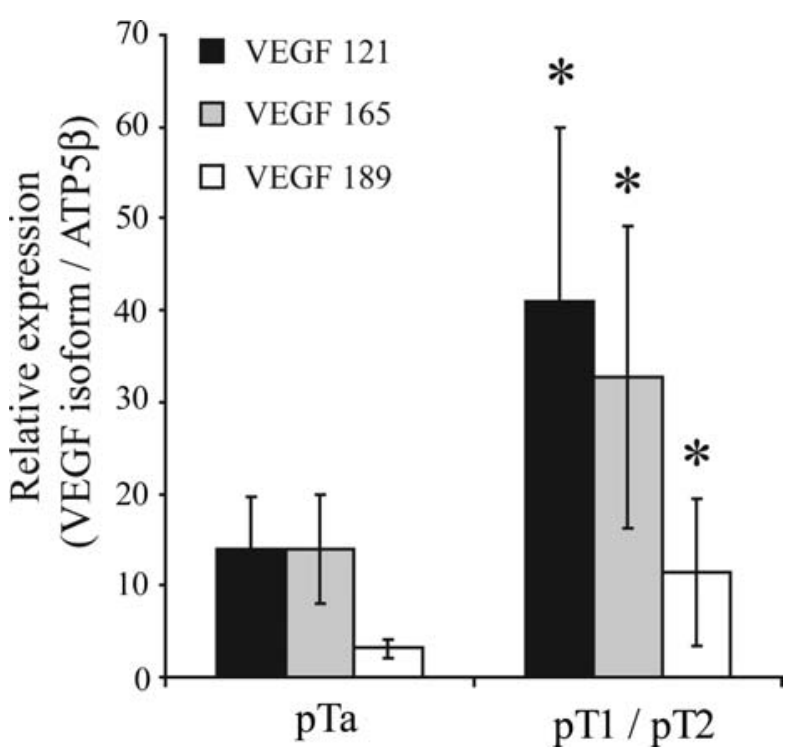

Figure 4. Quantitative analysis of VEGF-A isoform expression in noninvasive ( $\mathrm{pTa}$ ) versus invasive (pT1-T2) urothelial tumors. Total RNA was isolated from $8 \mathrm{pTa}, 7 \mathrm{pT} 1$ and 5 pT2 bladder tumors. VEGF-A isoform transcript levels were measured by real-time RT-PCR and normalized to ATP5ß. Data are presented as the mean \pm SEM. ${ }^{*}$ p $<0.05$, Mann-Whitney U test.

isoforms were also observed in normal urothelium and in pTa tumors (data not shown) whereas VEGF206 expression was absent in all cases. Results obtained from RT4 cells confirmed those previously observed (23). These data revealed the existence of three VEGF-A isoforms (121, 165 and 189) in bladder cancer. Nevertheless, the Southern blotting is not a quantitative method. That is why we used the real-time RTPCR, a highly sensitive and accurate technique, to quantify each isoform in the following experiments.
A
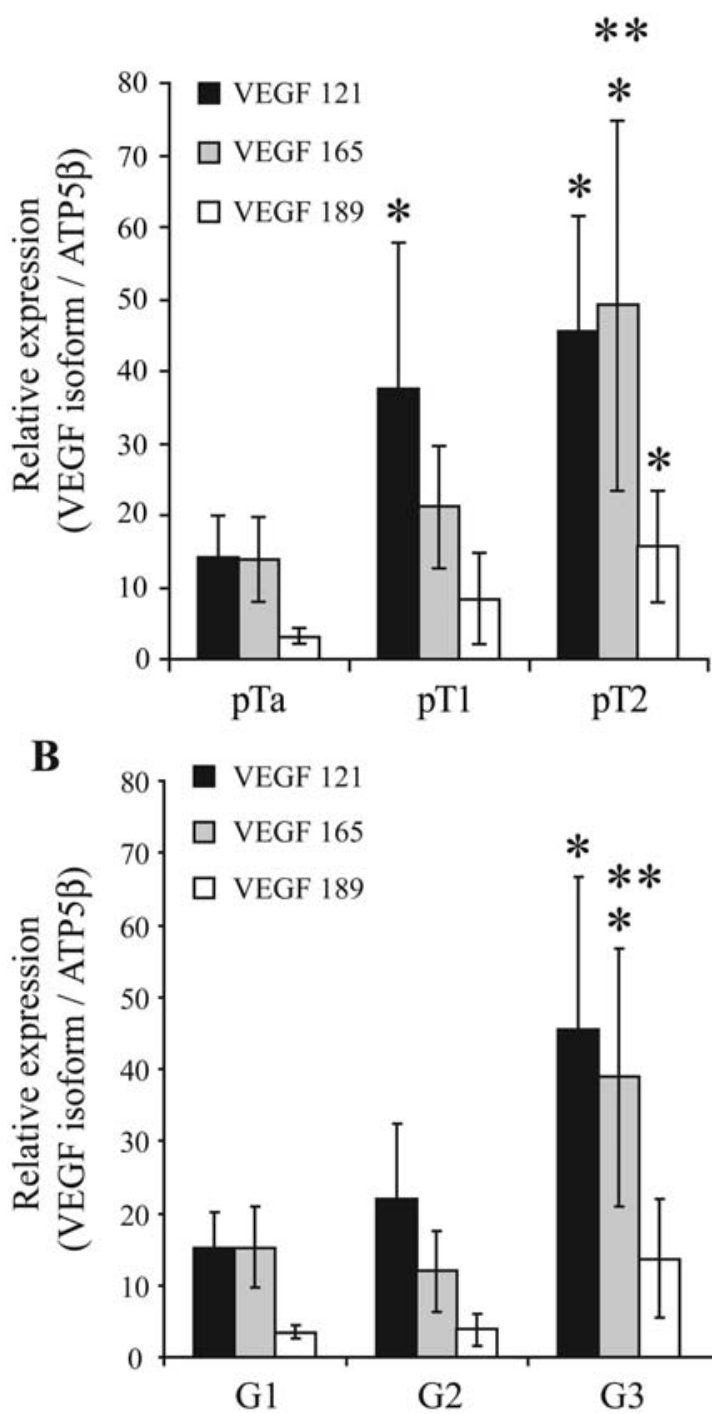

Figure 5. Quantitative analysis of VEGF-A isoform expression according to the pathologic stage (A) and to the histologic grade (B). Total RNA was isolated from 8 pTa, 7 pT1 and 5 pT2 bladder tumors. VEGF-A isoforms transcript levels were measured by real-time RT-PCR and normalized to ATP5ß. Data are presented as the mean \pm SEM. ${ }^{*} \mathrm{p}<0.05$, compared to $\mathrm{pTa}$ or G1 tumor, Mann-Whitney U test. ${ }^{* *} \mathrm{p}<0.05$, compared to $\mathrm{pT} 1$ or G2 tumor, Mann-Whitney U test.

Quantitative analysis of the different VEGF-A isoform expression in non-invasive and invasive bladder cancer samples using RTqPCR. We examined VEGF-A isoform transcript levels in 8 pTa, 7 pT1 and 5 pT2 tumors by realtime RT-PCR. VEGF121 and VEGF165 were expressed at similar level. On the contrary, both isoforms were significantly more expressed than VEGF189 (Friedmann and Wilcoxon tests; p<0.001). VEGF121, VEGF165 and VEGF189 were more highly expressed in pT1 or pT2 bladder cancers than in pTa tumors ( $p=0.003, p=0.017, p=0.025$ respectively (Fig. 4).

Correlation between VEGF-A isoform expression level and clinicopathological features. We evaluated the possible correlation between the expression pattern of VEGF-A splice variants and the pathological stage and the histological grade 
(Fig. 5). The variance among the three subgroups of patients with different tumor stage lesions was significant (KruskalWallis test; $\mathrm{p}=0.006$ for VEGF121, $\mathrm{p}=0.011$ for VEGF165, $\mathrm{p}=0.019$ for VEGF189). Paired comparison of the various groups revealed that levels of VEGF121 transcripts significantly increased in pT1 tumors $(\mathrm{p}<0.05)$ and in pT2 tumors $(\mathrm{p}<0.05)$ compared to $\mathrm{pTa}$ tumors. There was no statistically significant difference between pT1 and pT2 tumors for this isoform. The VEGF165 transcripts were significantly increased in pT2 tumors compared to pTa and pT1 tumors $(\mathrm{p}<0.05)$ but there was no statistically significant difference between pTa and pT1 tumors for this isoform. The expression level of VEGF189 was significantly increased in muscleinvasive carcinomas compared to pTa tumors $(\mathrm{p}<0.05)$ but there was no difference between pTa and pT1 tumors or between pT1 and pT2 tumors. The whole patient group was then subdivided into G1, G2 and G3 grade tumors and the respective VEGF-A isoform transcript levels were compared to those found in G1 grade lesions. The variance among the subgroups of patients with different grade lesions was only significant for VEGF121 and VEGF165 (KruskalWallis test; $\mathrm{p}=0.020$ for VEGF121, $\mathrm{p}=0.008$ for VEGF165, $\mathrm{p}=0.057$ for VEGF189). An increase of VEGF121 transcript level was observed in $\mathrm{G} 3$ grade bladder cancers in comparison with $\mathrm{G} 1$ grade lesions $(\mathrm{p}<0.05)$. Patients with $\mathrm{G} 1$ lesions did not significantly differ in their VEGF121 mRNA levels from patients with $\mathrm{G} 2$ tumors. VEGF165 transcript level was significantly increased in high grade G3 tumors compared to $\mathrm{G} 1$ and $\mathrm{G} 2$ lesions $(\mathrm{p}<0.05)$. As for VEGF121, patients with G1 lesions did not significantly differ in their VEGF165 mRNA levels from patients with G2 tumors.

\section{Discussion}

To gain insights into the molecular-genetic pathways and the biological role of angiogenesis in urothelial carcinogenesis, several studies investigated VEGF-A expression at both the mRNA and protein levels. But the reported findings are controversial. Moreover, to date, there are no data with regard to the expression of VEGF-B in bladder cancer. Its function is unclear since it is not required for angiogenesis. However, VEGF-B expression has been detected in a wide variety of tumors such as breast carcinoma, melanoma and fibrosarcoma (24-26), neuroblastomas (27), colorectal cancer (28), oral squamous cell carcinomas (29), and often in conjunction with VEGF-A and other angiogenic factors. Moreover, its ability to activate VEGFR1 and neuropilin-1 indicates that it represents a potential anti-cancer target. Up to the present time, its clinical relevance in bladder cancer remains to be established. In our study, we did not detect VEGF-B mRNA in urothelial tumors suggesting the absence of this VEGF family member in pathologic bladder. Thus, it seems that VEGF-B does not supplement the role of VEGF-A in promoting tumor angiogenesis in the course of urothelial carcinogenesis.

VEGF-A mRNA is markedly up-regulated in the majority of human tumors (12). But finally, few studies have been performed on VEGF-A expression at the mRNA level in bladder cancer. From 30 patients with TCC of the urinary bladder, Sato et al (18) detected by Northern blot hybridization analysis three VEGF-A transcripts of $5.5 \mathrm{~kb}, 4.4 \mathrm{~kb}$ and $3.7 \mathrm{~kb}$. The same transcripts have also been observed in human colon carcinoma cells (30). In the present work, we explored by Northern blotting the VEGF-A mRNA expression in bladder tumors and analysed its relationship to the tumor stage and grade. As already reported $(18,30)$, we displayed two VEGF-A transcripts of 5.2, $4.5 \mathrm{~kb}$. On the contrary, we did not reveal the $3.7 \mathrm{~kb}$ transcript and we detected for the first time to our knowledge in bladder cancer samples a shorter transcript of $1.7 \mathrm{~kb}$ in length. These three transcripts of 5.5, 4.5 and $1.7 \mathrm{~kb}$ had been already observed in a previous work performed in RT4 and T24 bladder cancer cell lines (31). This $1.7 \mathrm{~kb}$ transcript could be another VEGF-A isoform. Our Southern blot analysis revealed the expression of VEGF121, VEGF165, VEGF189 in both bladder cancer cell lines (RT4, T24) and bladder cancer tissues whatever the tumor stage. We detected neither VEGF145 nor VEGF206. Computer analysis indicates that the size of the known transcript VEGF-A isoform was between $3.5 \mathrm{~kb}$ and $5.5 \mathrm{~kb}$. This argues for the detection of a putative new isoform of $1.7 \mathrm{~kb}$. This new transcript was revealed by Northern blotting since the probe is a 610 bp cDNA fragment (19) which hybridizes near the atg transcription initiation site. Thus, this probe is able to detect all VEGF-A transcripts. On the contrary, the $1.7 \mathrm{~kb}$ transcript was not detected in Southern blotting. The upstream and downstream specific primers used to analyse the different VEGF-A isoforms are localized on exons 4 and 8 respectively. The putative new VEGF-A splice variant could have a truncated exon 8 or no exon 8 . In these conditions, it could be visualized by Northern blotting but undetectable by Southern blotting since there would have been no amplification by RT-PCR. An inhibitor splice variant of VEGF165, named VEGF165b, was described with a truncated exon 8 , increasing the complexity of VEGF-A signaling. VEGF165b inhibits VEGF165-mediated endothelial cell proliferation and migration $(32,33)$.

The prognostic value of VEGF-A expression within the bladder tumor remains to be clearly established. O' Brien et al (17) reported that the expression of VEGF-A predominates in pT1 tumors and is 10 times greater than in normal bladder and 4 times more expressed than in invasive tumors $(\geq \mathrm{pT} 2)$ according to RNAse protection assay. In a study of 55 patients presenting pT1G1 and pT1G2 tumors, it has been noted that superficial bladder cancer (pTa and pT1) with higher VEGF-A mRNA levels appeared to have earlier recurrence, a greater risk of stage progression and a shortened diseasefree survival. Thus, VEGF-A mRNA appeared to be an independent prognostic indicator for both recurrence and stage progression of pT1 bladder cancer (34). Using real-time RTqPCR, Quentin et al (35) demonstrated that low-stage superficial TCC expressed VEGF-A mRNA at a significantly higher level than high-stage muscle-invasive carcinomas. On the contrary, Sato et al (18) demonstrated that pT2-T4 TCC showed greater VEGF-A gene expression than pT1 tumors. Using a colorimetric in situ hybridization technique, Izawa et al (36) observed that VEGF-A expression was increased in muscle-invasive disease compared to pTa tumors and CIS. Slaton and colleagues (37) found that high expression of VEGF-A is a strong predictor of disease specific survival in patients with locally advanced TCC. Pignot et al 
(38) demonstrated by quantitative real-time RT-PCR that VEGF-A was significantly overexpressed in tumor samples compared to normal bladder tissue. In addition, VEGF-A was increased in pTa and pT1 tumors versus muscle-invasive bladder carcinomas. For invasive tumors, VEGF-A overexpression at a 13-month median follow-up was associated in univariate analysis with poor outcome and in multivariate analysis as an independent prognostic factor in both overall and disease-free survival.

In the present work, we showed similarly to Sato et al (18) that the expression of the three VEGF-A transcripts was greater in TCC compared to normal bladder tissue and muscle-invasive carcinomas had higher levels of VEGF-A than pTa and pT1 urothelial tumors. Furthermore, we noted that patients with TCC of the bladder expressing high VEGF-A mRNA levels (above a cut-off value) appeared to have a shortened progression-free survival for the three transcripts detected. Both 5.2 and $1.7 \mathrm{~kb}$ transcripts correlated to the pathologic stage, the histologic grade and the presence of carcinoma in situ. On the other hand, the $4.5 \mathrm{~kb}$ transcript only correlated to the pathologic stage. Kaplan-Meier survival analysis demonstrated that the $4.5 \mathrm{~kb}$ transcript overexpression was associated with a poorer prognosis of disease progression compared to the other two transcripts. On these bases, further prospective studies may be undertaken to establish whether closer follow-up might be beneficial in patients with bladder cancer that express high levels of the $4.5 \mathrm{~kb}$ transcript.

The controversy in the status of the vegf- $A$ gene expression between all these studies could lie in sampling procedure. Non-invasive pTa and pT1 bladder tumors are usually protruding intraluminally and can be obtained by TUR without contamination by surrounding normal mucosa and smooth muscle. Samples obtained by TUR from invasive tumors could be contaminated by normal tissue. VEGF-A expression has been reported to be much lower in the smooth muscle cells and the fibroblasts than in the epithelial cells (39). Thus, a tissue sample contaminated with smooth muscle possibly expresses less VEGF-A. In our study, invasive TCC are obtained from surgical specimens of total cystectomy under direct vision in order to exclude underlying or surrounding smooth muscle layer. Thus, we believe that our results reported the real VEGF-A expression in each tissue specimen.

Despite all these investigations the prognostic value of VEGF-A in bladder cancer is not convincingly established. That is why we take great interest in the expression of its isoforms. Several studies showed that some VEGF-A splice variants expression was related to tumor progression. VEGF189 expression is correlated with poor prognosis in colon cancer, oesophageal cancer, and non-small cell lung cancer (40-42). VEGF121 mRNA expression level in lung cancer presenting lymph node metastasis was higher than in cancer without metastasis (43). Few studies have focused on the expression of VEGF-A isoforms in bladder cancer.

In our study, we detected three VEGF-A splice variants namely VEGF189, VEGF165 and VEGF121 by Southern blotting and each was quantified by RTqPCR methodology. The VEGF206 was absent. These results are in agreement with those previously obtained by Crew and co-workers (34).
On the contrary, they are different from those published by O'Brien et al (17) who displayed only VEGF121 and VEGF165 isoforms with the VEGF121 as the major one. In the same way, Li et al (44) have detected mRNA expression of four VEGF-A isoforms namely VEGF121, 165, 189 and 206. The levels of VEGF206 and VEGF189 in pT2 tumors were significantly lower than those in pTa and pT1 tumors. In contrast, the levels of VEGF121 in pT2 tumors tended to be higher than those in pTa and pT1 tumors. The differences could be due to the methodology used. A study revealed by RTqPCR the expression of 6 isoforms from 157 urothelial tumor bladder samples: VEGF121, VEGF145, VEGF148, VEGF165, VEGF183, and VEGF189 (38). All isoforms were significantly overexpressed in tumor samples as compared to normal bladder tissue. Overexpression of VEGF121, VEGF148, VEGF183, and VEGF189 was statistically significant in high grade pT1 versus pT2 tumors. Overexpression of VEGF121, VEGF148, VEGF165, VEGF183, and VEGF189 was statistically significant in pTa and pT1 versus pT2 tumors.

Our results revealed that VEGF121, 165 and 189 were overexpressed in pT1-pT2 tumors versus pTa tumors. We did not detect VEGF148 and VEGF183 splice variants. The expression of the three detected isoforms increased according to the tumor stage and grade. VEGF121 and 165 were expressed to the same extent whatever the tumor stage and the histologic grade. VEGF189 was the lowest expressed isoform in pTa, pT1 and pT2 tumors as in G1, G2 and G3 tumors. On the whole, the results suggest that the distribution of VEGF-A splice variants might play a role in tumor progression of bladder cancer. It is worth noting that in bladder cancer the major isoforms are the secreted soluble isoforms which are in fact the more rapidly available forms to allow tumor growth.

At the protein level, studies on the prognostic value of VEGF-A are also contradictory. Whatever the technique used, immunohistochemistry $(45,46)$ or the measurement of VEGF-A in biological fluids by ELISA $(47,48)$ the controversy in the status of VEGF-A in bladder cancer remains unresolved. However, in a previous study, we noted that elevated serum level of VEGF-A was associated with the progression of pT1 tumors. Most importantly, it was associated with bladder cancer metastasis. With a cut-off of $400 \mathrm{pg} / \mathrm{ml}$ it was possible to differentiate patients with and without metastatic disease. Although VEGF-A did not remain an independent prognostic factor, the level of VEGF-A might be a valuable angiogenic marker for identifying metastatic bladder cancer (49).

In conclusion, the current data indicate that high VEGF-A mRNA level might be a prognostic indicator of progression as well as the expression level of the different VEGF-A splice variants. However, further investigations on larger cohorts are required to validate our preliminary results relating to the expression pattern of VEGF-A isoforms.

\section{Acknowledgements}

We thank Catherine Vial for her technical assistance. This work was supported by grants from a 'Programme régional Hospitalier de Recherche Clinique' (Besançon, France), the 
'Ligue Nationale Contre le Cancer' (Comités du Doubs et du Jura, Besançon, France).

\section{References}

1. Dalesio O, Schulman CC, Sylvester R, De Pauw M, Robinson M, Denis L, Smith P and Viggiano G: Prognostic factors in superficial bladder tumors. A study of the European Organization for Research on Treatment of Cancer: Genitourinary Tract Cancer Cooperative Group. J Urol 129: 730-733, 1983.

2. Heney NM, Proppe K, Prout GR Jr, Griffin PP and Shipley WU: Invasive bladder cancer: tumor configuration, lymphatic invasion and survival. J Urol 130: 895-897, 1983.

3. Levi F, La Vecchia C, Randimbison L and Franceschi S: Incidence of infiltrating cancer following superficial bladder carcinoma. Int J Cancer 55: 419-421, 1993.

4. Lee R and Droller MJ: The natural history of bladder cancer. Implications for therapy. Urol Clin North Am 27: 1-13, vii, 2000.

5. Droller MJ: Markers in bladder cancer-issues to consider. J Urol 160: 2009-2010, 1998

6. Ferrara N: Vascular endothelial growth factor: basic science and clinical progress. Endocr Rev 25: 581-611, 2004

7. Tischer E, Mitchell R, Hartman T, Silva M, Gospodarowicz D, Fiddes JC and Abraham JA: The human gene for vascular endothelial growth factor. Multiple protein forms are encoded through alternative exon splicing. J Biol Chem 266: 1194711954,1991

8. Poltorak Z, Cohen T, Sivan R, Kandelis Y, Spira G, Vlodavsky I, Keshet E and Neufeld G: VEGF145, a secreted vascular endothelial growth factor isoform that binds to extracellular matrix. J Biol Chem 272: 7151-7158, 1997.

9. Neufeld G, Cohen T, Gengrinovitch S and Poltorak Z: Vascular endothelial growth factor (VEGF) and its receptors. FASEB J 13: 9-22, 1999 .

10. Dvorak HF, Brown LF, Detmar M and Dvorak AM: Vascular permeability factor/vascular endothelial growth factor, microvascular hyperpermeability, and angiogenesis. Am J Pathol 146: 1029-1039, 1995.

11. Houck KA, Leung DW, Rowland AM, Winer J and Ferrara N: Dual regulation of vascular endothelial growth factor bioavailability by genetic and proteolytic mechanisms. J Biol Chem 267: 26031-26037, 1992.

12. Ferrara $\mathrm{N}$ and Davis-Smyth T: The biology of vascular endothelial growth factor. Endocr Rev 18: 4-25, 1997.

13. Olofsson B, Pajusola K, Kaipainen A, von Euler G, Joukov V, Saksela O, Orpana A, Pettersson RF, Alitalo K and Eriksson U: Vascular endothelial growth factor B, a novel growth factor for endothelial cells. Proc Natl Acad Sci USA 93: 2576-2581, 1996.

14. Maglione D, Guerriero V, Viglietto G, Ferraro MG, Aprelikova O, Alitalo K, Del Vecchio S, Lei KJ, Chou JY and Persico MG: Two alternative mRNAs coding for the angiogenic factor, placenta growth factor (PlGF), are transcribed from a single gene of chromosome 14. Oncogene 8: 925-931, 1993.

15. Karamysheva AF: Mechanisms of angiogenesis. Biochemistry (Mosc) 73: 751-762, 2008.

16. Brown LF, Berse B, Jackman RW, Tognazzi K, Manseau EJ, Dvorak HF and Senger DR: Increased expression of vascular permeability factor (vascular endothelial growth factor) and its receptors in kidney and bladder carcinomas. Am J Pathol 143: $1255-1262,1993$.

17. O'Brien T, Cranston D, Fuggle S, Bicknell R and Harris AL: Different angiogenic pathways characterize superficial and invasive bladder cancer. Cancer Res 55: 510-513, 1995.

18. Sato K, Sasaki R, Ogura Y, Shimoda N, Togashi H, Terada K, Sugiyama T, Kakinuma H, Ogawa $\mathrm{O}$ and Kato T: Expression of vascular endothelial growth factor gene and its receptor (flt-1) gene in urinary bladder cancer. Tohoku J Exp Med 185: 173-184, 1998.

19. Chin K, Kurashima Y, Ogura T, Tajiri H, Yoshida S and Esumi H: Induction of vascular endothelial growth factor by nitric oxide in human glioblastoma and hepatocellular carcinoma cells. Oncogene 15: 437-442, 1997.

20. Olofsson B, Korpelainen E, Pepper MS, Mandriota SJ, Aase K, Kumar V, Gunji Y, Jeltsch MM, Shibuya M, Alitalo K and Eriksson U: Vascular endothelial growth factor B (VEGF-B) binds to VEGF receptor-1 and regulates plasminogen activator activity in endothelial cells. Proc Natl Acad Sci USA 95: 11709-11714, 1998.
21. Pfaffl MW: A new mathematical model for relative quantification in real-time RT-PCR. Nucleic Acids Res 29: 2003 2007, 2001

22. Andersen CL, Jensen JL and Orntoft TF: Normalization of real-time quantitative reverse transcription-PCR data: a modelbased variance estimation approach to identify genes suited for normalization, applied to bladder and colon cancer data sets. Cancer Res 64: 5245-5250, 2004

23. Chabannes E, Fauconnet S, Bernardini S, Wallerand H, Adessi G and Bittard $\mathrm{H}$ : Protein kinase $\mathrm{C}$ signalling pathway is involved in the regulation of vascular endothelial growth factor expression in human bladder transitional carcinoma cells. Cell Signal 13: 585-591, 2001

24. Gunningham SP, Currie MJ, Han C, Robinson BA, Scott PA, Harris AL and Fox SB: VEGF-B expression in human primary breast cancers is associated with lymph node metastasis but not angiogenesis. J Pathol 193: 325-332, 2001.

25. Mylona E, Alexandrou P, Giannopoulou I, Liapis G, Sofia M, Keramopoulos A and Nakopoulou L: The prognostic value of vascular endothelial growth factors (VEGFs)-A and -B and their receptor, VEGFR-1, in invasive breast carcinoma. Gynecol Oncol 104: 557-563, 2007.

26. Salven P, Lymboussaki A, Heikkila P, Jaaskela-Saari H, Enholm B, Aase K, von Euler G, Eriksson U, Alitalo K and Joensuu H: Vascular endothelial growth factors VEGF-B and VEGF-C are expressed in human tumors. Am J Pathol 153: 103-108, 1998.

27. Eggert A, Ikegaki N, Kwiatkowski J, Zhao H, Brodeur GM and Himelstein BP: High-level expression of angiogenic factors is associated with advanced tumor stage in human neuroblastomas. Clin Cancer Res 6: 1900-1908, 2000.

28. Kawakami M, Furuhata T, Kimura Y, Yamaguchi K, Hata F, Sasaki K and Hirata K: Expression analysis of vascular endothelial growth factors and their relationships to lymph node metastasis in human colorectal cancer. J Exp Clin Cancer Res 22: 229-237, 2003 .

29. Shintani S, Li C, Ishikawa T, Mihara M, Nakashiro K and Hamakawa H: Expression of vascular endothelial growth factor $\mathrm{A}, \mathrm{B}, \mathrm{C}$, and D in oral squamous cell carcinoma. Oral Oncol 40: 13-20, 2004

30. Koura AN, Liu W, Kitadai Y, Singh RK, Radinsky R and Ellis LM: Regulation of vascular endothelial growth factor expression in human colon carcinoma cells by cell density. Cancer Res 56: 3891-3894, 1996.

31. Fauconnet S, Lascombe I, Chabannes E, Adessi GL, Desvergne B, Wahli W and Bittard H: Differential regulation of vascular endothelial growth factor expression by peroxisome proliferatoractivated receptors in bladder cancer cells. J Biol Chem 277: 23534-23543, 2002.

32. Bates DO, Cui TG, Doughty JM, Winkler M, Sugiono M, Shields JD, Peat D, Gillatt D and Harper SJ: VEGF165b, an inhibitory splice variant of vascular endothelial growth factor, is down-regulated in renal cell carcinoma. Cancer Res 62: 4123-4131, 2002

33. Cui TG, Foster RR, Saleem M, Mathieson PW, Gillatt DA, Bates DO and Harper SJ: Differentiated human podocytes endogenously express an inhibitory isoform of vascular endothelial growth factor (VEGF165b) mRNA and protein. Am J Physiol Renal Physiol 286: F767-F773, 2004.

34. Crew JP, O'Brien T, Bradburn M, Fuggle S, Bicknell R, Cranston D and Harris AL: Vascular endothelial growth factor is a predictor of relapse and stage progression in superficial bladder cancer. Cancer Res 57: 5281-5285, 1997.

35. Quentin T, Schlott T, Korabiowska M, Kathei N, Zoller G, Glaser $\mathrm{F}$ and Kunze E: Alteration of the vascular endothelial growth factor and angiopoietins- 1 and -2 pathways in transitional cell carcinomas of the urinary bladder associated with tumor progression. Anticancer Res 24: 2745-2756, 2004.

36. Izawa JI, Slaton JW, Kedar D, Karashima T, Perrotte P, Czerniak B, Grossman HB and Dinney CP: Differential expression of progression-related genes in the evolution of superficial to invasive transitional cell carcinoma of the bladder. Oncol Rep 8: 9-15, 2001.

37. Slaton JW, Millikan R, Inoue K, Karashima T, Czerniak B, Shen Y, Yang Y, Benedict WF and Dinney CP: Correlation of metastasis related gene expression and relapse-free survival in patients with locally advanced bladder cancer treated with cystectomy and chemotherapy. J Urol 171: 570-574, 2004. 
38. Pignot G, Bieche I, Vacher S, Guet C, Vieillefond A, Debre B, Lidereau R and Amsellem-Ouazana D: Large-scale real-time reverse transcription-PCR approach of angiogenic pathways in human transitional cell carcinoma of the bladder: identification of VEGFA as a major independent prognostic marker. Eur Urol (In press).

39. Berse B, Brown LF, Van de Water L, Dvorak HF and Senger DR: Vascular permeability factor (vascular endothelial growth factor) gene is expressed differentially in normal tissues, macrophages, and tumors. Mol Biol Cell 3: 211-220, 1992.

40. Oshika Y, Nakamura M, Tokunaga T, Ozeki Y, Fukushima Y, Hatanaka H, Abe Y, Yamazaki H, Kijima H, Tamaoki N and Ueyama Y: Expression of cell-associated isoform of vascular endothelial growth factor 189 and its prognostic relevance in non-small cell lung cancer. Int J Oncol 12: 541-544, 1998.

41. Tokunaga T, Kijima H, Oshika Y, Fukushima Y, Abe Y, Ohnishi Y, Yamazaki H, Tsuchida T, Makuuchi H, Tamaoki N, Ueyama $\mathrm{Y}$ and Nakamura M: Aberrant isoform of vascular endothelial growth factor 189 expression is correlated with xenotransplantability of human esophageal cancer. Oncol Rep 5: 1115-1118, 1998.

42. Tokunaga T, Oshika Y, Abe Y, Ozeki Y, Sadahiro S, Kijima H, Tsuchida T, Yamazaki H, Ueyama Y, Tamaoki N and Nakamura M: Vascular endothelial growth factor (VEGF) mRNA isoform expression pattern is correlated with liver metastasis and poor prognosis in colon cancer. Br J Cancer 77: 998-1002, 1998.

43. Ohta Y, Watanabe Y, Murakami S, Oda M, Hayashi Y, Nonomura A, Endo Y and Sasaki T: Vascular endothelial growth factor and lymph node metastasis in primary lung cancer. Br J Cancer 76: 1041-1045, 1997.
44. Li N, Kanda K, Fukumori T, Inoue Y, Nishitani M, Kanayama H and Kagawa S: Expression of vascular endothelial growth factor isoforms and platelet-derived endothelial cell growth factor in bladder cancer. Urol Oncol 6: 10-15, 2000.

45. Chow NH, Liu HS, Chan SH, Cheng HL and Tzai TS: Expression of vascular endothelial growth factor in primary superficial bladder cancer. Anticancer Res 19: 4593-4597, 1999.

46. Stavropoulos NE, Bouropoulos C, Ioachim IE, Michael M, Hastazeris K, Tsimaris I, Kalogeras D, Liamis Z, Stefanaki S and Agnantis NI: Prognostic significance of angiogenesis in superficial bladder cancer. Int Urol Nephrol 36: 163-167, 2004.

47. Crew JP, O'Brien T, Bicknell R, Fuggle S, Cranston D and Harris AL: Urinary vascular endothelial growth factor and its correlation with bladder cancer recurrence rates. J Urol 161: 799-804, 1999

48. Miyake H, Hara I, Yamanaka K, Gohji K, Arakawa S and Kamidono S: Elevation of serum level of vascular endothelial growth factor as a new predictor of recurrence and disease progression in patients with superficial urothelial cancer. Urology 53: 302-307, 1999.

49. Bernardini S, Fauconnet S, Chabannes E, Henry PC, Adessi G and Bittard H: Serum levels of vascular endothelial growth factor as a prognostic factor in bladder cancer. J Urol 166: 1275-1279, 2001. 